BLACK, R. W. \& ELSTAD, P. Instrumental and consummatory behavior as a function of length or reward period. Psychonomic Science, 1964, 1, 301-302.

CAMMIN, W. Quantitative and qualitative shifts in reward in instrumental conditioning. Unpublished doctoral dissertation, University of South Carolina, 1968

CILLUFFO, A., \& BLACK, R. W. Runway performance maintained by multiple rewards per trial. Psychonomic Science, $1970,19,19-20$.

GUILD, R. E. Incentive motivation in satiated rats. Journal of Comparative \& P hysiological Psychology, 1960, 53, 351-358.

HIERS, J. M. Persistence of contrast effects following repeated shifts in reward in instrumental conditioning. Unpublished doctoral dissertation, University of South Carolina, 1968.

HULSE, S. H., SNYDER, H. L., \& BACON, W. E. Instrumental licking behavior as a function of schedule, volume, and concentration of a saccharine reinforcement. Journal of Experimental Psychology, 1960, 60, 359-364.

KLING, J. $W$. Speed of running as a function of goal box behavior. Joumal of Comparative \& Physiological Psychology $1956,49,474-476$.

PUBOLS, $B$. $H$. Incentive magnitude and learning and performance in animals. Psychological Bulletin, 1960, 57, 89-15.

SNY DER, H. L., \& HULSE, S. H. Effect of volume of reinforcement and number of consummatory responses on licking and running behavior. Journal of Experimental Psychology, 1961, 61, 474-479.

STELLAR, E., \& HILL, J. H. The rat's rate of drinking as a function of water deprivation. Journal of Comparative \& Physiological Psychology, 1952, 45 , 96-102.

WIKE, E. L \& BARRIENTOS, G, Selective learning as a function of differential consummatory activity. Psychological Reports, 1957, 3, 255-258.

WINER, B. J. Statistical principles in experimental design. New York: McGraw-Hill, 1962.

\title{
A multivariate study of competition in a free-operant situation
}

\author{
ROBERT S. RUSKIN and CHARLES D. CORMAN \\ West Virginia University, Morgantown, W. Va. 26505
}

Hooded rats were tested in a competitive free operant situation under three levels of food deprivation: 24, 48, and $72 \mathrm{~h}$. Pearson product moment correlations, performed on the six measures analyzed at each level, showed significant intercorrelations among all but one of the measures. Level of deprivation did not significantly affect the degree of intercorrelation among the measures. Possible explanations for the high degree of relationship among the scores at each level of deprivation were discussed.

Competition in rodents consists of many responses occurring in rapid succession. The analysis of such complex sequences of behavior emitted by each of two or more members in the competing group has presented a great problem to researchers in the area.

This problem has been attacked in two different ways. First, the researcher may decide to focus his attention on one specific behavior being emitted by each member of the competing group (e.g., Hsaio \& Schreiber, 1968; Uyeno, 1968; Corman \& Ruskin, 1969). The assumption made with this type of approach is that the single behavior being studied in each animal adequately reflects success or lack of success in competition. This assumption may not be valid.

The second approach consists of analyzing several of the behaviors being emitted by each animal in a social situation and, on the basis of differentials found in these behaviors, making the decision as to the relative "dominance" or "submissiveness" of each member (e.g., Baenniger, 1966; Candland \& Bloomquist, 1965). There are also problems inherent in this type of procedure. When scoring many behaviors from each of two or more Ss in a single session, several scorers are needed. The problem of reliability of scoring among individual scorers then becomes of primary importance.

The utilization of a free operant situation, in conjunction with videotaped replays, permits a multivariate analysis of competitive behavior and also allows one individual to analyze consistently all of the behaviors being emitted in a given competitive situation.

Six measures were isolated in the free operant competitive situation. Three of the measures were considered by the Es to reflect behaviors present in a "limited access" competitive situation: the number of responses made by a competitor in the nose poke (i.e., the number of penetrations into the nose-poke opening); the number of crossovers in responding from one competitor to the other (i.e., the number of times that competing $\mathrm{Ss}$ alternated in responding); and the amount of time each competitor spent positioned in front of the nose poke. The other three measures were considered to reflect more closely behaviors present in a "social encounter" type of situation: the number of "sparring" responses initiated by one competitor toward the other, the number of biting responses initiated, and the number of $9 \times 9$ in. grid floor segments traversed.

The purpose of this study was (1) to determine the degree of relationship among the six measures, (2) to determine if any differential relationships existed among measures more closely related to "limited access" or "social encounter" situations, and (3) to establish whether or not these relationships changed significantly with changes in levels of deprivation.

\section{SUBJECTS}

Forty-eight male hooded rats, 60 days old at the beginning of testing, were used. All Ss were housed separately from weaning in a constant-temperature and light-dark condition ( $12 \mathrm{~h}$ on $/ 12 \mathrm{~h}$ off). APPARATUS

Paired competitive testing occurred in a nose-poke apparatus.

The nose-poke cpartment was $18 \times 18$ in., with plywood walls and grid floor. The nose-poke opening was $11 / 4$ in. in diam and positioned in the middle of one wall. Food was delivered by standard delivery mechanisms. The foodcup was located directly behind the nose-poke opening.

Penetrations were recorded, and reinforcement presented through the use of a photoelectric cell unit mounted inside the opening.

CCTV equipment was used in conjunction with the nose-poke apparatus to facilitate immediate recording and later scoring of all 
Table 1

Product-Moment Correlations for Three Levels of Deprivation

\begin{tabular}{|c|c|c|c|c|c|c|c|}
\hline & & $\mathbf{1}$ & 2 & $\mathbf{3}$ & 4 & $\mathbf{5}$ & 6 \\
\hline & & Table 1a: & 24 Hours & & & & \\
\hline Number of Responses & 1 & & & & & & \\
\hline Number of Crossovers & 2 & -.53 & & & & & \\
\hline TPIN & 3 & .69 & -.68 & & & & \\
\hline Sparring & 4 & .51 & -.67 & .52 & & & \\
\hline Biting & 5 & .28 & -.20 & .18 & .79 & & \\
\hline Locomotion & 6 & -.49 & .48 & -.81 & -.53 & -.22 & \\
\hline \multicolumn{8}{|l|}{$r=.3613 \quad p<.01$} \\
\hline & & Table 1b: & 48 Hours & & & & \\
\hline Nunber of Responses & $\mathbf{1}$ & $\operatorname{sen}^{2}$ & & & & & \\
\hline $\begin{array}{l}\text { Number of Crossovers } \\
\text { TPIN }\end{array}$ & 2 & -.62 & & & & & \\
\hline TPIN & $\mathbf{3}$ & .61 & -.57 & & & & \\
\hline Sparring & 4 & .46 & -.59 & .40 & & & \\
\hline Biting & 5 & .19 & -.27 & .20 & .83 & & \\
\hline Locomotion & 6 & -.57 & .64 & -.87 & -.41 & -.39 & \\
\hline \multicolumn{8}{|l|}{$r=.3613 \quad p<.01$} \\
\hline & & Table 1c: & 72 Hours & & & & \\
\hline Number of Responses & $\mathbf{1}$ & & & & & & \\
\hline Number of Crossovers & 2 & -.58 & & & & & \\
\hline TPIN & 3 & .72 & -.56 & & & & \\
\hline Sparring & 4 & .60 & -.58 & .49 & & & \\
\hline Biting & 5 & .21 & -.16 & .17 & .91 & & \\
\hline Locomotion & 6 & -.59 & .51 & -.87 & -.50 & -.42 & \\
\hline$r=.3613 \quad p<.01$ & & & & & & & \\
\hline
\end{tabular}

relevant competitive behaviors. The use of videotaping eliminated the need for several Es simultaneously scoring the same session.

\section{PROCEDURE}

All Ss were divided randomly into six groups of eight Ss each. No Ss of the same group were housed together either before or during testing.

The Ss were deprived of food for $24 \mathrm{~h}$ and then trained to make nose-poking responses in the apparatus. Once all Ss were performing maximally in the nose poke, deprivation and testing began. Each of the six groups was tested under three deprivation conditions-24, 48, and $72 \mathrm{~h}$-and differed only in the order of presentation of conditions.

In the 24-h deprivation condition, all Ss were deprived of food for $24 \mathrm{~h}$ and were paired randomly within each group in the nose poke. Competitive behaviors were recorded during each 15-min test session. Twenty-four pairings, four per group, were recorded in this condition. The 48- and 72-h conditions were identical in procedure with the 24-h condition, except that the level of deprivation was increased.

Each of the six groups received 3 days of ad lib feeding in their home cages between each test condition. Time of day and temperature were also held constant during testing.

\section{RESULTS AND DISCUSSION}

Pearson product moment correlations were calculated among all measures for the three levels of deprivation.

In the 24-, 48- and 72-h deprivation conditions, nonsignificant correlations $(p>.01)$ were found between biting and three other measures: number of responses emitted, number of crossovers, and time positioned in front of the opening. The correlation between biting and locomotion was also nonsignificant $(p>.01)$ in the 24-h condition. Intercorrelations among all other measures were significant for all levels of deprivation. It is interesting to note that level of deprivation had little, if any, effect on the degree of intercorrelation (Tables $1 a, 1 b$, and $1 c)$.

The high degree of intercorrelation among five of the six measures in each of the deprivation conditions may, at least in part, be a function of a lack of independence resulting from aspects of the procedure. For example, the time positioned in front of the nose poke would be influenced by locomotion, since both are mutually exclusive. Other strong relationships would be expected between the number of responses an $\mathbf{S}$ makes and the number of crossovers, as well as between sparring and biting.

The low intercorrelations found between biting and most of the other measures could simply be a function of the extremely low absolute number of bites emitted during a single test session.

Two of the measures analyzed, locomotion and the number of crossovers, were found to be negatively correlated with the other four measures. This relationship exists because of the nature of the measures used. Ss which are successful in competition tended to have few crossovers and manifest low locomotion scores. This is reasonable, since both measures are decreased by high scores in the measures of time positioned in front of the nose-poke opening and number of responses emitted.

On the basis of these data, there seems to be a high degree of relationship in success of competition over both measures relating to "limited access" and "social encounter," and this relationship appears to be little affected by the level of deprivation under which the members of the group are competing.

A possible explanation for these relationships may simply be that $S$ s are "situationally" dominant or submissive. This would mean, for example, that for any level of deprivation a given "dominant" S would be predisposed to rank highly in all of the dominance-related measures in thy test situation (Leary \& Maroney, 1962; Ruskin \& Corman, 1971)

The utilization of videotaping provides the $E$ the opportunity of classifying and analyzing all the behaviors which may be present in a given competitive situation. This technique has a distinct advantage over those procedures which have analyzed single behaviors in a competitive setting, since the behavior chosen as the criterion measure may not, in fact, adequately reflect success in competition.

Further research should be undertaken to isolate more behaviors in the competitive situation so that a more complete understanding may be gained of the complexities of this phenomenon.

\section{REFERENCES}

BAENNINGER, $L$. $P$. The reliability of dominance orders in rats. Animal Behaviour, 1966, 14, 367-371.

CANDLAND, D. K., \& BLOOMQUIST, D. $W$. Interspecies comparisons of the reliability of dominance orders. Journal of Comparative \& Physiological Psychology, 1965, 59, 135-137.

CANDLAND, D. K., MATTHEWS, T. J., \& TAYLOR, D. B. Factors affecting reliability and dominance orders in the domestic chicken. Journal of Comparative \& Physiological Psychology. $1968,66,168-174$

CORMAN, C. D., \& RUSKIN, R. S. Free operant competition under two schedules of reinforcement. Paper presented at annual meetings of the Psychonomic Society, 1969.

HSAIO, S., \& SCHREIBER, S. C. Social dominance and motivational variables in rats. Psychonomic Science, 1968, 10 , 117-118.

LEARY, R, W. \& MARONEY, R. J. The effects of home-cage environment on the social dominance of monkeys. Journal of Comparative \& Physiological Psychology, 1962, 55, 256-259.

RUSKIN, R. S., \& CORMAN, C. D. The relationship among dominance hierarchies determined in three competitive situations. Paper to be presented at the annual Eastern Psychological Association. 1971 .

UYENO, E. T., \& WHITE, M. Sex and dominance behavior in the rat Psychonomic Science, 1968, 13, 192. 